\title{
Phenotypic Variation in Skull Size and Shape Between Newfoundland and Mainland Populations of North American Black Bears, Ursus americanus
}

\author{
John A. VIRGL ${ }^{1}$, SHANe P. MAHONEY² ${ }^{2}$ and Kim MAWHINNEY ${ }^{3}$ \\ ${ }^{1}$ Ecological Development and Statistical Analysis, 222 Haight Place, Saskatoon, Saskatchewan S7H 4W2 Canada \\ ${ }^{2}$ Science Division, Wildlife and Protected Areas, P. O. Box 8700, Department of Tourism, Culture, and Recreation, St. John's, \\ Newfoundland A1B 4J6 Canada \\ ${ }^{3}$ Canadian Wildlife Service, Environment Canada, 6 Bruce Street, Mount Pearl, Newfoundland A1N 4T3 Canada
}

\begin{abstract}
Virgl, John A., Shane P. Mahoney, and Kim Mawhinney. 2003. Phenotypic variation in skull size and shape between Newfoundland and mainland populations of North American Black Bears, Ursus americanus. Canadian Field-Naturalist 117(2): 236-244.
\end{abstract}

It is well recognized that differences in environmental selection pressures among populations can generate phenotypic divergence in a suite of morphological characteristics and associated life history traits. Previous analysis of mitochondrial DNA and body size have suggested that Black Bears (Ursus americanus) inhabiting the island of Newfoundland represent a different subspecies or ecotype from mainland populations. Assuming that body size covaries positively with skull size, we predicted that skull size would be greater for bears on the island than the mainland, and the distribution of size-related shape components in multivariate space should show a distinct separation between Newfoundland and mainland populations. Measurements of 1080 specimens from Newfoundland, Alberta, New York, and Quebec did not provide unequivocal support for our prediction that skull size in Newfoundland bears would be larger than bears from the mainland populations. After removing ontogenetic effects of skull size, between-population variation in skull shape was greater in females than males, and the analysis significantly separated Newfoundland bears from mainland populations. Explanations for this pattern are numerous, but currently remain hypothetical. Limited covariation between skull size and body size suggests that genetic traits regulating the size of Black Bear skulls are more heritable (i.e., less influenced by environmental selection pressures) than characteristics affecting body size. We hypothesize that if gape size does not limit prey size in solitary terrestrial carnivores, large degrees of among-population variation in body size should be coupled with little covariation in skull size. In general, sexual dimorphism in skull size and shape was marginal for the phenotypic characters measured in our study. We believe that sexual dimorphism in skull size in Black Bears is primarily driven by intrasexual selection in males for increased gape size display, while similarity in skull shape between sexes is associated with the constraints of a temporally-selective, but similar diet.

Key Words: Black Bear, Ursus americanus, heritability, ontogeny, multivariate analysis, Newfoundland.

Several studies have used multivariate and univariate techniques on skull and jaw characteristics of carnivores to separate taxonomic groups or generate testable hypotheses about the processes driving morphological variation within species and between sexes (Rausch 1963; Ralls and Harvey 1985; Wiig 1989; Gittleman and Valkenburgh 1997; Chestin and Mikeshina 1998). Determining the relative importance of environmental selection and genetic factors (i.e., degree of heritability) on phenotypic covariance/variance among populations is fundamental for understanding the evolutionary divergence of populations into distinct species or subspecies (Felsenstein 1988; Armbruster and Schwaegerle 1996). However, while some phenotypic traits may respond quickly to local environmental conditions and result in measurable differences among geographically distinct populations, other characteristics may be inherently less flexible and exhibit little or no difference among populations. For example, pleiotropy, gene linkage, and/or phylogeny can constrain natural selection and limit the evolutionary divergence of one or more phenotypic characteristics (Harvey and Mace 1982;
Lande 1982; Arnold 1992). Furthermore, as demonstrated by Roff (2000) in a genetic analysis of body size, growth rate, fecundity and development, it is not always possible to predict the direction of covariation among phenotypic traits.

Black Bears (Ursus americanus) on the island of Newfoundland were originally described as a new subspecies (U. a. hamiltoni) based on several cranial characteristics of 19 skulls from eastern Canada (Cameron 1956). Despite this limited sample, recent mitochondrial DNA analysis has provided partial support for the subspecies status of this population (Paetkau and Strobeck 1996). These authors suggested that the limited genetic divergence between Newfoundland and mainland populations occurred after the Wisconsin ice age through rapid genetic drift in a small isolated founder population (Paetkau and Strobeck 1996). Furthermore, a recent analysis of body size in Black Bears between Newfoundland and five mainland populations indicated that Newfoundland bears were significantly larger than individuals on the mainland (Mahoney et al. 2001). Larger size in Newfoundland 
bears was theoretically attributed to a number of environmental selection pressures; the principal factor being the ability of an individual to exploit seasonally abundant and spatially dispersed dietary protein (Mahoney et al. 2001).

If historic/current differences in environmental selection pressures between island and mainland Black Bear populations exert similar effects on body size and skull size, then phenotypic variation in skull size between island and mainland populations should positively covary with patterns in body size. We examined this hypothesis through a multivariate analysis of four skull measurements from 1080 Black Bears collected from Newfoundland and three mainland populations. Specifically, we predicted that skull size would be greater for bears on the island than the mainland, and the distribution of size-related shape components in multivariate space should show a distinct separation between Newfoundland and mainland populations. We also report on the degree of sexual dimorphism among the four populations.

\section{Materials and Methods}

\section{Skull measurements and geographic populations}

Skulls were collected from four geographically distinct populations in North America: Alberta, Quebec, Newfoundland, and New York. Morphometric, sex, and age data were obtained from bears killed by hunters during the spring or autumn. A standard protocol, describing the linear measurements, units and precision, was used to ensure that the linear attributes for each measurement were identical (see below). Age of individuals, except young of the year, was determined using standard techniques for counting cementum annuli (Willey 1974). We accept that part of the phenotypic variation in skull size and shape may be associated with differences in size-dependent human hunting mortality, but assume that this selection mechanism is cursory in explaining the patterns observed here.

Four measurements were recorded to the nearest $1 \mathrm{~mm}$. Condylobasal length (CBL) was measured as the distance, along the midline, from a line connecting the most posterior margins of the alveoli of the upper incisors to a line connecting the most posterior margins of the condyles. Zygomatic breadth (ZB) was recorded as the greatest distance across the zygomatic arches. Mastoid breadth (MB) was measured as the greatest width of the skull across the mastoid bones or processes. Mandibular length (ML) was recorded as the greatest length of one ramus of the lower jaw (not including any part of a tooth).

\section{Statistical analysis}

Data were pooled by sex and population to provide eight comparable groups, and all measurements were log-transformed prior to analysis (Wiig 1989; Lynch et al. 1997). These groups were then used to perform three separate analyses. The first two analyses examined among-population variation for females and males, independently. The third analysis used all eight groups in a single canonical variate analysis to calculate morphological (Mahalanobis, $D^{2}$ ) distance between sexes, which provides an index of sexual dimorphism (Wiig and Andersen 1986; Lynch et al. 1997).

When several groups (i.e., sexes and populations) are involved in a multivariate analysis, single group principal component analysis (PCA) is not suitable for separating the between-group structure expected among populations (Thorpe 1988; Wiig 1989). Therefore, we used the pooled within-group covariance matrix to conduct PCA (termed multiple group principal component analysis (MGPCA)) on skull measurements for female and male Black Bears from geographic populations. As with single group PCA, positive eigenvectors (correlation coefficients) for the morphometric measures indicate that the first principal component (PC1) in MGPCA is associated with size variation that can be explained by allometric or ontogenetic scaling (i.e., size-age relationship), and is uncorrelated with shape variation (Lynch et al. 1997). The remaining principal components (PCs) largely represent variation in skull shape. For each sex-specific PC, a one-way analysis of variance was conducted to examine the degree of betweenpopulation variation in skull size and shape components. The PCs were then entered into a canonical variate analysis (CVA) to test for significant multivariate differences among populations, while correcting for sample size. CVA was performed once using all PCs ("size-in" analysis) and a second time excluding PC1 ("size-out" analysis; Lynch and Hayden 1995; Lynch et al. 1997). Comparison of these two analyses provides a means of determining the contribution of size and size-related shape structure to the variation among populations (Lynch et al. 1997). Interpretation of the significance of shape components was based on asymptotic statistical procedures (Lynch et al. 1996). Reallocation rates were statistically compared to the expected $25 \%$ rate ( $100 \%$ / 4 groups) using Cohens Kappa $(K)$ and associated 95\% CI.

All statistical analyses were performed with the SAS statistical package for microcomputers (Version 6.07). SAS / IML programs for the MGPCA and Cohens Kappa were written and performed by John M. Lynch (Arizona State University).

\section{Results}

Geographic variation in skull size and shape

A total of 1080 Black Bear skulls ranging from cub of the year to 25 years of age were used in the analyses (Table 1). Non-parametric one-way ANOVA (Kruskal-Wallis test) indicated that there was significant variation in age composition among the sampled populations for female $\left(\chi^{2}=7.84, d f=3, P=0.05\right)$ and male $\left(\chi^{2}=16.14, d f=3, P<0.01\right)$ bear skulls. Much of this variation appears to be associated with the maximum age of skulls collected from the popu- 
TABLE 1. Age composition (years) of skull samples for female and male Black Bears collected from geographic populations in North America. COY $=$ cub of the year.

\begin{tabular}{|c|c|c|c|c|c|c|}
\hline \multirow[b]{2}{*}{ Population } & \multicolumn{3}{|c|}{ Females } & \multicolumn{3}{|c|}{ Males } \\
\hline & $\mathrm{N}$ & $\begin{array}{c}\text { Mean } \\
(\min , \max ) \\
\end{array}$ & $\begin{array}{c}\text { Median } \\
(95 \text { Percentile) }\end{array}$ & $\mathrm{N}$ & $\begin{array}{c}\text { Mean } \\
(\min , \max ) \\
\end{array}$ & $\begin{array}{c}\text { Median } \\
\text { (95 Percentile) }\end{array}$ \\
\hline Alberta & 13 & $3.9(\mathrm{COY}, 13)$ & $2(13)$ & 48 & $4.7(\mathrm{COY}, 16)$ & $3(13)$ \\
\hline Newfoundland & 154 & $5.2(\mathrm{COY}, 23)$ & $4(14)$ & 265 & $5.4(\mathrm{COY}, 22)$ & $4(14)$ \\
\hline New York & 184 & $5.7(1,21)$ & $4(15)$ & 263 & $4.3(\mathrm{COY}, 25)$ & $3(13)$ \\
\hline Quebec & 74 & $5.1(1,17)$ & $4(13)$ & 79 & $3.9(1,20)$ & $3(10)$ \\
\hline
\end{tabular}

lations (Table 1). However, the median age of skulls ( 2 - 4 years) and the 95 percentile $(10-15$ years) across populations indicates that there is a good representation of skulls that are approaching or have reached asymptotic size within all groups, except females from Alberta (four skulls were greater than four years of age).

Examination of the variation in three individual skull measurements among populations suggests that, on average, females from Newfoundland and New York have larger skulls than females from Alberta and Quebec (Table 2). Although Newfoundland females had slightly longer (CBL) and wider (MB and $\mathrm{ZB}$ ) skulls than New York females, the difference was marginal compared to the other populations. In contrast, within males, bears from Alberta had the longest skulls (CBL), but skull breadth was similar among bears from Alberta, Newfoundland and New York, and smallest for individuals from Quebec (Table 2). For both sexes, patterns in jaw length (ML) showed little correlation with measurements of skull length and breadth.

Multiple group principal component analysis indicated that PC1 explained over $80 \%$ of the variation in female and male skull measurements within populations (\%WGV), while PC2 and PC3 essentially accounted for all of the remaining variation (Table 3). PC1 was positively correlated with all four skull characteristics which constitutes significant ontogenetic or allometric size variation (Wiig 1992; Lynch et al.
1997). PC1 also explained a significant amount of between-population variation $(\% \mathrm{BGV})$ in female and male bears (Table 3), but did not separate Newfoundland from mainland populations (Figure 1). Similar to the data for individual skull measurements, PC1 indicated that females from Quebec have smaller skulls than females from Newfoundland and New York, while males from Quebec have smaller skulls than males from Newfoundland, New York and Alberta. These patterns of univariate and multivariate skull measurements do not support our prediction that Newfoundland Black Bears would have larger skulls than bears from mainland populations.

PC2 and PC3 were positively and negatively correlated with skull measurements which reflect variation in skull shape (Table 3). For females, all four skull measurements were significantly $(P<0.05)$ associated with PC2 and PC3, but within males, mastoid breadth was not significantly correlated with PC2. Within females, all three principal components resulted in a significant separation of the populations, but PC2 and PC3 explained more between-population variation than PC1. In contrast, the between-population variation accounted for by the three components was similar within males, and significant (Table 3). Overall, the results from the MGPCA indicate that $\mathrm{PC} 1$ is strongly associated with age-related changes in female and male skull size among Black Bear populations. Thus, the reader must be aware that PC1 not only contains growth-related changes in skull size, but also contains

TABLE 2. Mean \pm 1 SE condylobasal length (CBL), mastoid breadth (MB), zygomatic breadth (ZB), and mandibular length (ML) for female (F) and male (M) North American Black Bears among populations. All variables were measured to the nearest $1 \mathrm{~mm}$. ( ) = number of individuals. $\mathrm{AB}=$ Alberta, NFD = Newfoundland, NY = New York, QB = Quebec.

\begin{tabular}{|c|c|c|c|c|c|c|c|c|}
\hline \multirow[b]{2}{*}{ Population } & \multicolumn{2}{|c|}{ CBL } & \multicolumn{2}{|c|}{ MB } & \multicolumn{2}{|c|}{ ZB } & \multicolumn{2}{|c|}{ ML } \\
\hline & $\mathrm{F}$ & M & $\mathrm{F}$ & M & $\mathrm{F}$ & M & $\mathrm{F}$ & M \\
\hline $\mathrm{AB}$ & $\begin{array}{c}213.4 \pm 12.4 \\
\text { (13) }\end{array}$ & $\begin{array}{c}288.8 \pm 5.2 \\
(48)\end{array}$ & $\begin{array}{c}98.0 \pm 6.0 \\
(13)\end{array}$ & $\begin{array}{c}120.7 \pm 3.0 \\
(48)\end{array}$ & $\begin{array}{l}128.7 \pm 8.1 \\
\quad(13)\end{array}$ & $\begin{array}{c}157.0 \pm 4.0 \\
(48)\end{array}$ & $\begin{array}{c}<60.0 \pm 14.7 \\
(13)\end{array}$ & $\begin{array}{c}184.6 \pm 1.1 \\
48)\end{array}$ \\
\hline NFD & $\begin{array}{c}239.6 \pm 1.6 \\
(154)\end{array}$ & $\begin{array}{c}257.2 \pm 1.7 \\
(265)\end{array}$ & $\begin{array}{c}109.6 \pm 1.0 \\
(154)\end{array}$ & $\begin{array}{c}119.8 \pm 1.1 \\
(265)\end{array}$ & $\begin{array}{c}147.9 \pm 1.7 \\
(154)\end{array}$ & $\begin{array}{c}160.0 \pm 1.6 \\
(265)\end{array}$ & $\begin{array}{c}164.1 \pm 1.2 \\
(154)\end{array}$ & $\begin{array}{l}176.9 \pm 1.2 \\
\quad(265)\end{array}$ \\
\hline NY & $\begin{array}{c}233.3 \pm 1.2 \\
(184)\end{array}$ & $\begin{array}{c}254.3 \pm 1.5 \\
(263)\end{array}$ & $\begin{array}{c}106.9 \pm 0.9 \\
(184)\end{array}$ & $\begin{array}{c}117.3 \pm 1.0 \\
(263)\end{array}$ & $\begin{array}{c}142.8 \pm 1.3 \\
\quad(184)\end{array}$ & $\begin{array}{c}155.8 \pm 1.5 \\
(263)\end{array}$ & $\begin{array}{c}171.0 \pm 1.1 \\
(184)\end{array}$ & $\begin{array}{c}184.6 \pm 1.1 \\
\quad(263)\end{array}$ \\
\hline QB & $\begin{array}{c}226.0 \pm 2.7 \\
(74)\end{array}$ & $\begin{array}{c}234.4 \pm 3.5 \\
(79)\end{array}$ & $\begin{array}{c}101.5 \pm 1.4 \\
(74)\end{array}$ & $\begin{array}{c}103.8 \pm 1.9 \\
(79)\end{array}$ & $\begin{array}{c}128.2 \pm 3.6 \\
(74)\end{array}$ & $\begin{array}{c}135.3 \pm 4.0 \\
(79)\end{array}$ & $\begin{array}{c}171.9 \pm 3.1 \\
(74)\end{array}$ & $\begin{array}{c}172.7 \pm 3.6 \\
(79)\end{array}$ \\
\hline
\end{tabular}


TABle 3. Principal component coefficients for skull measurements within female and male Black Bears from four North American populations. Component coefficients are provided for those variables which have an asymptotic standard error to coefficient ratio greater than 3.0. All other coefficients were deemed to be not significant (NS). \%WGV is the within-group variation explained by each component. $\% \mathrm{BGV}$ is the between-group variation explained by each component. Results from ANOVAs $(F, P)$ for examination of between-group differences for each component are also provided. Abbreviations for skull measurements are provided in Table 2 .

\begin{tabular}{lccccccc}
\hline \hline & \multicolumn{3}{c}{ Females } & & \multicolumn{3}{c}{ Males } \\
\cline { 2 - 4 } & PC1 & PC2 & PC3 & & PC1 & PC2 & PC3 \\
\hline CBL & 0.38 & 0.23 & 0.28 & & 0.40 & 0.22 & -0.14 \\
MB & 0.50 & 0.17 & 0.69 & & 0.54 & NS & -0.75 \\
ZB & 0.63 & -0.73 & -0.27 & & 0.62 & -0.66 & 0.42 \\
ML & 0.46 & 0.62 & -0.61 & 0.41 & 0.72 & 0.49 \\
\%WGV & 80.1 & 15.1 & 3.9 & 87.7 & 8.2 & 3.1 \\
\%BGV & 6.8 & 12.9 & 14.4 & & 7.3 & 8.4 & 5.2 \\
F & 10.29 & 20.87 & 23.69 & & 17.21 & 19.82 & 12.00 \\
P & $<0.01$ & $<0.01$ & $<0.01$ & $<0.01$ & $<0.01$ & $<0.01$ \\
\hline \hline
\end{tabular}

some variation in age composition among populations (Table 1). PC2 and PC3 reflect between-population differences in size-related skull shape, but the relative amount of variation explained by these two components was greater within females than males.

Subsequent analysis of the canonical variates for "size-in" and "size-out" skull structure within females resulted in significant separation between most populations (Wilks' $\lambda>0.64, P<0.001$ ). After removing ontogenetic effects, Mahalanobis distances (corrected for sample size) between canonical variate scores indicated that female skull structure was different between all populations, except Alberta and New York (Figure 2). This result was confirmed by reallocation rates. For example, re-substitution of individual skulls to different populations was significantly $(P<0.01)$ greater than expected by chance for all populations ( $K=0.46 \pm 0.07)$, except for Alberta and New York $(P=0.05$, adjusted a for multiple comparisons $=0.008)$.

For male bears, there was also significant variation in "size-in" and "size-out" canonical variates between populations (Wilks' $\lambda>0.77, P<0.001$ ). Following removal of age-dependent size effects, re-substitution analysis indicated that only the Mahalanobis distance (corrected for sample size) between canonical variate scores for the Newfoundland and mainland populations was significant $(P<0.01)$. Thus, most of the individuals were being reallocated at a rate similar to that expected by chance $(K=0.30 \pm 0.06)$ which is exemplified by the large degree of overlap between populations from Alberta, Quebec and New York (Figure 2). Overall, these results support the prediction that sizerelated skull shape in female and male Newfoundland Black Bears would be significantly different than bears from the mainland populations.

\section{Sexual Dimorphism}

As expected for carnivores, skull length and skull breadth were greater in male bears than female bears
(Table 2). The eight-group MGPCA indicated that all three principal components explained a significant amount of between-group variation $(P<0.001)$. The relative amount of between-group variance explained by $\mathrm{PC} 1, \mathrm{PC} 2, \mathrm{PC} 3$ was $14.2 \%, 10.9 \%$ and $8.5 \%$, respectively. All skull measurements were significantly and positively correlated with PC1, while the correlation between measurements and PC2 and PC3 was positive and negative (all were significant). Thus, differences in female and male skull size was associated with PC1, while PC2 and PC3 separated female and male bears based on differences in skull shape.

Results from the "size-in" and "size-out" CVAs indicated that sexual dimorphism in skull size and shape was greatest in bears from Alberta and least in bears from Newfoundland (Table 4). Size-dependent dimorphism was relatively greater in New York bears than Quebec bears, and shape-dependent dimorphism was relatively greater in the Quebec population than the New York population (Table 4). For bears from Alberta and Newfoundland, differences in skull structure ("size-out" analysis) between sexes was largely due to the second canonical variate (PC3), while differences between female and male bears from Quebec was associated with the first canonical variate (PC2). Both canonical variates appeared equally important in separating female and male bears from New York.

\section{Discussion}

Based on the measurements of skull length and breadth used in this study we could not find unequivocal support for our prediction that skull size would be significantly greater in Black Bears from Newfoundland than mainland populations. Newfoundland female skulls were slightly larger than female skulls from New York and significantly larger than individuals from Quebec. Skull size in male bears from Newfoundland was statistically larger than males from Quebec, but similar to males from Alberta and New 

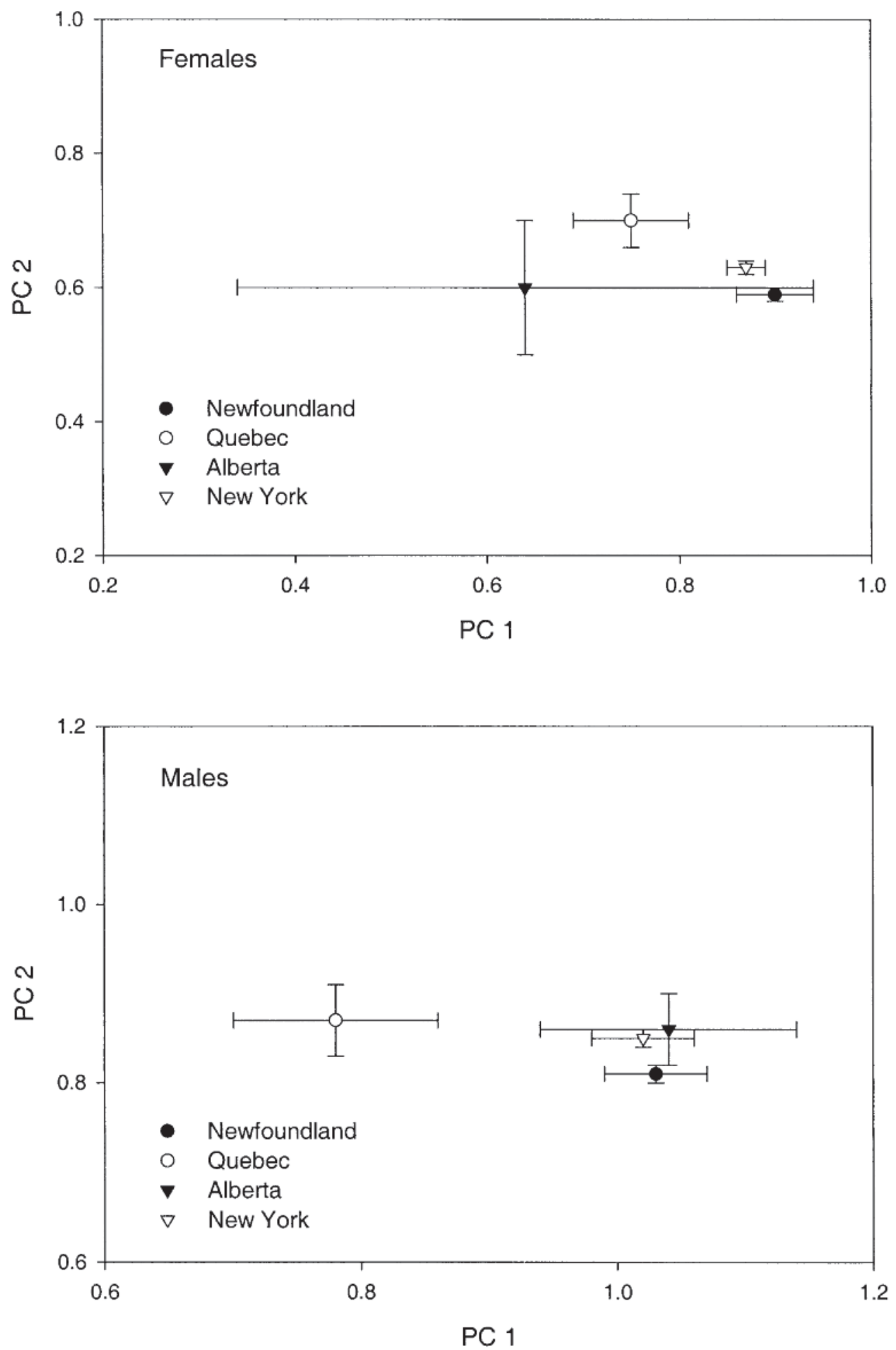

FIGURE 1. Distribution of skull size (PC 1) and shape (PC 2) components for female and male Black Bears from four North American populations. Bars represent $2 \mathrm{SE}$ around the mean. 

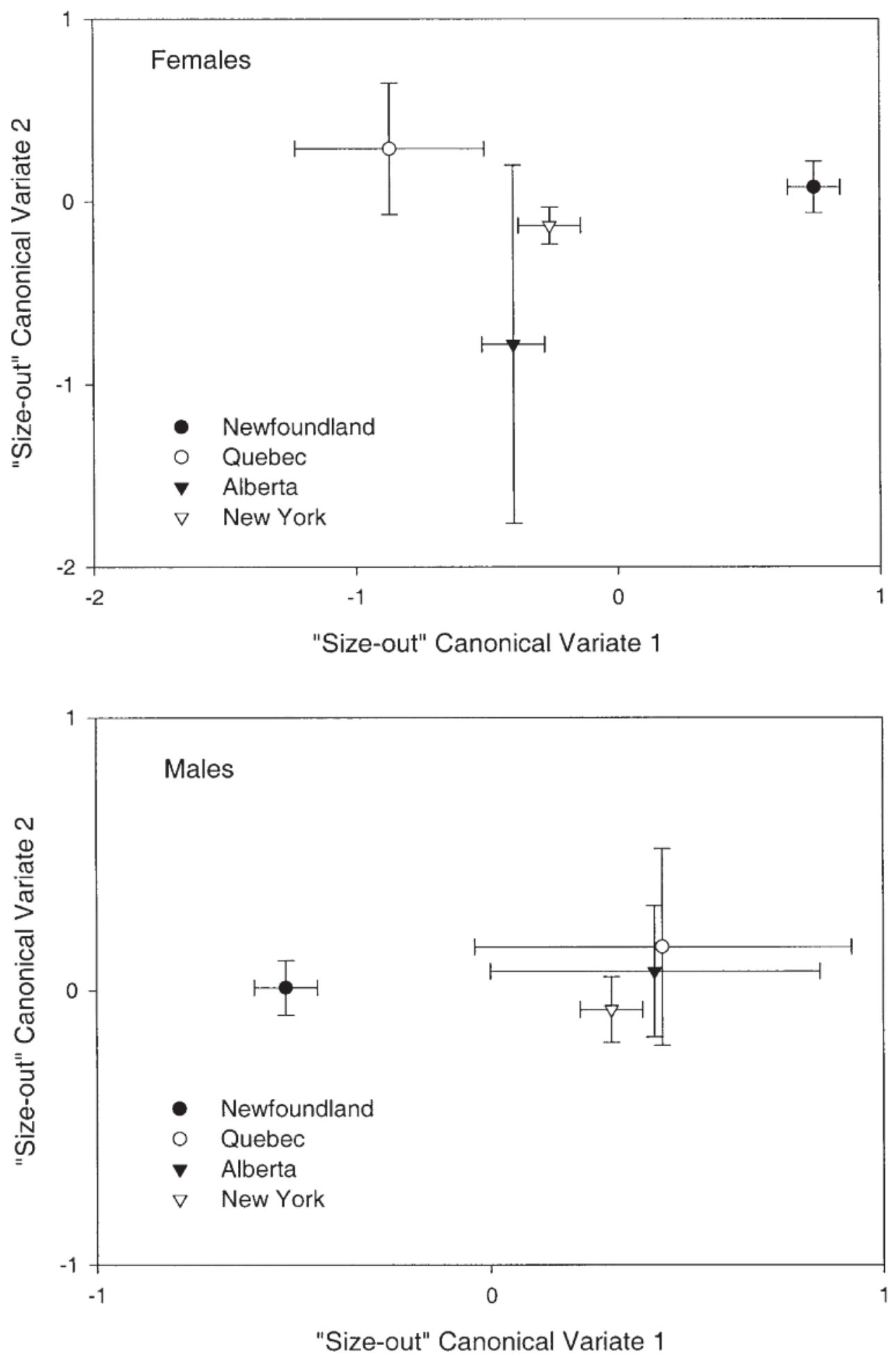

FIGURE 2. Distribution of skull shape ("size-out" analysis) components for female and male Black Bears from four North American populations. Bars represent $2 \mathrm{SE}$ around the mean. 
TABLE 4. Indices of degree of sexual dimorphism (SD) for Black Bear populations. Values represent Mahalanobis distances between sexes for an eight-group canonical variate analysis on principal component scores derived from MGPCA.

\begin{tabular}{lcc}
\hline \hline Population & "Size-in" SD & "Size-out" SD \\
\hline Alberta & 4.03 & 1.56 \\
Newfoundland & 0.41 & 0.10 \\
New York & 0.71 & 0.33 \\
Quebec & 0.61 & 0.58 \\
\hline \hline
\end{tabular}

York. Our prediction was formulated around a recent analysis of body size in Black Bears (Mahoney et al. 2001), and the assumption that abiotic and biotic environmental selection pressures should exert similar influences on body size and skull size so that the two attributes would exhibit positive covariation.

However, the observed degree of variation in sexdependent skull size among populations showed little covariance with the amount of variation in body size previously determined for Newfoundland and mainland Black Bear populations (Mahoney et al. 2001). In that analysis, the average relative difference in asymptotic body size between females from the island population and five mainland populations (New Brunswick, Quebec, Ontario, Maine and Alaska) was 55\%, while the relative difference between males was $37 \%$. Limited ontogenetic variation in skull size (i.e., between-group variation for PC1 was $6.8 \%$ and $7.3 \%$ for females and males, respectively) relative to body size variation suggests that selection on skull size is more constrained than body size in North American Black Bears. Because the skull and dentition represent the principal killing apparatus in carnivores, constraints on optimal skull size (and shape) should be strong. However, relative to most freshwater and marine predators, and some reptiles, terrestrial carnivores may be less constrained by gape size (Zaret 1980; DeMarco et al. 1985; Hairston and Hairston 1993; Shine 1996). For solitary terrestrial carnivores, maximum prey size is primarily determined by predator body size (Schoener 1969; Vézina 1985), and theoretically, constraints on selection for local adaptations in body size should be less than skull size. Body size should be able to respond more quickly (i.e., over ecological time), and over a wider range, to changing environmental conditions. We hypothesize that if gape size does not limit prey size in solitary terrestrial carnivores, then large degrees of among-population variation in body size should be coupled with little covariation in skull size. Alternatively, phenotypic variation in body size and skull size may covary among populations or ecotypes, but predicting the direction of covariation between traits may prove difficult (Roff 2000).

After removing ontogenetic effects (i.e., "size-out" analysis), our results clearly showed that skull shape was statistically different in female and male bears from Newfoundland relative to individuals from mainland populations. This pattern is even more striking when one considers the limited number of skull mea- surements used to separate island and mainland populations of Black Bears in multivariate space. For example, Cameron (1956) examined 12 cranial attributes in 19 Black Bear skulls from eastern Canada to identify bears from Newfoundland as a separate subspecies (U. a. hamiltoni). Other studies of North American Brown Bears, European Rabbits (Oryctolagus cuniculus), and European Roe Deer (Capreolus capreolus) found that skull morphometrics were inadequate for delineating subspecies, and suggested that genetic analysis should be performed to verify taxonomically dissimilar groups (Rausch 1963; Sharples et al. 1996; Aragon et al. 1998). A recent analysis of mitochondrial DNA using eight haplotypes also suggested that Black Bears from Newfoundland represent a separate subspecies from mainland populations, but there was no evidence for a strong phylogenetic split between groups (Paetkau and Strobeck 1996). Thus, it appears that the type of cranial measurements and analysis used here may provide an effective method for distinguishing between potentially different ecotypes of Black Bears across North America.

There are a number of potential abiotic and biotic factors, which are not mutually exclusive, that could be linked to the observed phenotypic variation in sizerelated skull shape among Black Bear populations. However, without explicit tests of the environmental selection pressures that may be driving between-population variation in skull shape, explanations are purely hypothetical. One factor(s) may be related to spatial and temporal differences in food availability, food items, and/or prey size. Empirical studies have correlated these "food factors" with body size in bears and other predators (Schoener 1969; Case 1978; Ferguson and McLoughlin 2000; Mahoney et al. 2001), but exactly how these elements of diet are related to skull shape is unclear. Variation in cranial shape may also be coupled with historical/current between-population differences in the strength of interspecific competition for food and prey, and subsequent character displacement and (or) release (Abrams 1996; Losos 1996; see Mikulová and Frynta (2001) for history and groups demonstrated). For example, during the past 80 years Black Bears have been the exclusive large carnivore on Newfoundland. Wolves (Canis lupus) were extirpated around 1920, and Coyotes (Canis latrans) have only inhabited the island since 1985 (Mahoney et al. 2001). Alternatively, phenotypic variation in Black Bear skulls may be the result of a neutral or non- 
adaptive mutation in the gene complex regulating cranial shape. Small degrees of variation could have arisen through chance events associated with rapid genetic drift in a small isolated founder population (Paetkau and Strobeck 1996; Slatkin 1996; Lynch et al. 1997).

Similar to the Eurasion Badger (Meles meles; Lynch et al. 1997), sexual dimorphism in skull size and shape among Black Bear populations was marginal. Except for the Alberta population (which is likely influenced by small sample size for females), Mahalanobis distances indicated that cranial structure in female and male bears was quite similar. Explanations for the evolution of sexual dimorphism include competitive character displacement, sex-specific differences in partitioning assimilated energy and protein towards somatic tissue growth and reproduction, and sexual selection for increased mating opportunities (Ralls 1977; Ralls and Harvey 1985; Quin et al. 1996; Gittleman and Valkenburgh 1997). But niche separation (character displacement) appears more closely coupled with sexual dimorphism in carnivore species that have a strong preference for animal protein (Ralls and Harvey 1985; Gittleman and Valkenburgh 1997). Although Black Bears are predatory (Mahoney 1986; Schwartz and Franzmann 1991), both female and male Black Bears across North America are sufficiently omnivorous to preclude niche separation as a principal factor driving sexual dimorphism in skull size and shape. For Black Bears, local distribution of prey size and availability, and phenology and dispersion of nutritious plant items is similar for each sex which minimizes the potential for competitive displacement in cranial attributes. While the energetic constraints of reproduction in females would exacerbate sexual dimorphism, we believe that the primary factor responsible for sex-specific differences in skull size in Black Bears is intrasexual selection for increased gape size display in males associated with a polygynous mating system (Bunnel and Tait 1981; Gittleman and Valkenburgh 1997).

Ewer (1973) and Wiig (1986) stipulated that the shape of the carnivore skull is primarily determined by brain size, and jaw and neck musculature (characteristics linked with mastication). If the masticatory apparatus in omnivorous carnivores is under similar selection pressures in both sexes, we should expect little difference in the shape of female and male skulls. Therefore, limited variation in skull shape between females and males may represent a functional adaptation for exploiting the seasonal variation in animal and plant foods available to Black Bears. We recognize, however, that this hypothesis is based on a limited number of skull characteristics and that an analysis using a larger array of cranial attributes may detect a greater degree of sexual dimorphism within and between populations. Thus, although the morphometric measurements used in this study were sufficient for separating Newfoundland and mainland Black Bear ecotypes, a broader suite of skull traits may be necessary for teasing apart any potential functional differences in cranial shape between female and male bears.

\section{Acknowledgments}

We thank the many staff of the Newfoundland and Labrador Wildlife Division, and the personnel from Gros Morne National Park and Terra Nova National Park. Our greatest appreciation is extended to the following people and government agencies who provided skull morphology data: L. Berchielli with the Wildlife Research Center, New York; H. Jolicoeur with the Government of Quebec, and J. R. Gunson with Alberta Environmental Protection, Fish and Wildlife Division. We benefited from the constructive comments of B. McLaren and T. Miller. We are extremely grateful for the statistical expertise and analysis provided by Dr. John M. Lynch (Arizona State University). Funding for this project was provided by the provincial government of Newfoundland and Labrador who have continued their commitment to the development of wildlife science.

\section{Literature Cited}

Abrams, P. A. 1996. Evolution and the consequences of species introductions and deletions. Ecology 77: 13211328.

Aragon, S., F. Braza, C. S. Jose, and P. Fandos. 1998. Variation in skull morphology of roe deer (Capreolus capreolus) in western and central Europe. Journal of Mammalogy 79: 131-140.

Armbruster, W. S., and K. E. Schwaegerle. 1996. Causes of covariation of phenotypic traits among populations. Journal of Evolutionary Biology 9: 261-276.

Arnold, S. J. 1992. Constraints on phenotypic evolution. American Naturalist 140: S85-S107.

Bunnel, F. L., and D. E. N. Tait. 1981. Population dynamics of bears - implications. Pages 75-98 in Dynamics of large mammal populations. Edited by C. W. Fowler and T. D. Smith. John Wiley \& Sons, New York, NY.

Cameron, A. W. 1956. A new black bear from Newfoundland. Journal of Mammalogy 37: 538-540.

Case, T. J. 1978. A general explanation for insular body size in terrestrial vertebrates. Ecology 59: 1-18.

Chestin, I. E., and N. G. Mikeshina. 1998. Variation in skull morphology of brown bears (Ursus arctos) from Caucasus. Journal of Mammalogy 79: 118-130.

DeMarco, V. G., R. W. Drenner, and G. W. Ferguson. 1985. Maximum prey size of an insectivorous lizard (Sceloporus undulatus garmani). Copeia 1985: 1077-1080.

Ewer, R. F. 1973. The carnivores. Weidenfeld and Nicholson, London, UK.

Felsenstein, J. 1988. Phylogenies and quantitative characters. Annual Review of Ecology and Systematics 19: 445-471.

Ferguson, S. H., and P. D. McLoughlin. 2000. Effect of energy availability, seasonality, and geographic range on brown bear life history. Ecography 23: 193-200.

Gittleman, J. L., and B. Valkenburgh. 1997. Sexual dimorphism in the canines and skulls of carnivores: effects of size, phylogeny, and behavioural ecology. Journal of Zoology (London) 242: 97-117.

Hairston, N. G., Jr, and N. G. Hairston. 1993. Cause-effect relationships in energy flow, trophic structure, and inter- 
specific interactions. American Naturalist 142: 379-411.

Harvey, P. H., and G. M. Mace. 1982. Comparisons between taxa and adaptive trends: problems and methodology. Pages 343-361 in Current problems in sociobiology. Edited by Kings College Sociobiology Group. Cambridge University Press, Cambridge, U.K.

Lande, R. 1982. A quantitative genetic theory of life history evolution. Ecology 63: 607-615.

Losos, J. B. 1996. Phylogenetic perspectives on community ecology. Ecology 77: 1344-1354.

Lynch, J. M., and T. J. Hayden. 1995. Genetic influences on cranial form: variation among ranch and feral American mink Mustela vison (Mammalia: Mustelidae). Biological Journal of the Linnaean Society 55: 293-307.

Lynch, J. M., J. W. H. Conroy, A. C. Kitchener, D. J. Jefferies, and T. J. Hayden. 1996. Variation in cranial form and sexual dimorphism among five European populations of otter Lutra lutra (L.). Journal of Zoology (London) 238: 81-96.

Lynch, J. M., R. Whelan, A. I. Il. Fituri, and T. J. Hayden. 1997. Craniometric variation in the Eurasian badger (Meles meles). Journal of Zoology (London) 242: 31-44.

Mahoney, S. P. 1986. The black bear in Newfoundland. Osprey 16: 10-21.

Mahoney, S. P., J. A. Virgl, and K. Mawhinney. 2001. Potential mechanisms for the phenotypic divergence in body size between Newfoundland and mainland black bear populations. Canadian Journal of Zoology 79: 16501660.

Mikulová, P., and D. Frynta. 2001. Test of character displacement in urban populations of Apodemus sylvaticus. Canadian Journal of Zoology 79: 794-801.

Paetkau, D., and C. Strobeck. 1996. Mitochondrial DNA and the phylogeography of Newfoundland black bears. Canadian Journal of Zoology 74: 192-196.

Quin, D. G., A. P. Smith, and T. W. Norton. 1996. Ecogeographic variation in size and sexual dimorphism in sugar gliders and squirrel gliders (Marsupialia: Petauridae). Australian Journal of Zoology 44: 19-45.

Ralls, K. 1977. Sexual dimorphism in mammals: avian models and unanswered questions. American Naturalist 111: 917-938.

Ralls, K., and P. H. Harvey. 1985. Geographic variation in size and sexual dimorphism of North American weasels. Biological Journal of the Linnaean Society 25: 119-167.
Rausch, R. L. 1963. Geographic variation in size in North American brown bears (Ursus arctos) as indicated by condylobasal length. Canadian Journal of Zoology 41: 33-45.

Roff, D. A. 2000. Trade-offs between growth and reproduction: an analysis of the quantitative genetic evidence. Journal of Evolutionary Biology 13: 434-445.

Schoener, T. W. 1969. Models of optimal size for solitary predators. American Naturalist 103: 277-313.

Schwartz, C. C., and A. W. Franzmann. 1991. Interrelationship of black bears to moose and forest succession in the northern coniferous forest. Wildlife Monographs 113: 158.

Sharples, C. M., J. M. Fa, and D. J. Bell. 1996. Geographical variation in size in the European rabbit (Oryctolagus cuniculus, Lagamorpha: Leporidae) in western Europe and North America. Zoological Journal of the Linnaean Society 117: $141-158$.

Shine, R. 1996. Life history evolution in Australian snakes: a path analysis. Oecologia 107: 484-489.

Slatkin, M. 1996. In defense of founder-flush theories of speciation. American Naturalist 147: 493-505.

Thorpe, R. S. 1988. Multiple group principal component analysis and population differentiation. Journal of Zoology (London) 216: 37-40.

Vézina, A. F. 1985. Empirical relationships between predator and prey size among terrestrial vertebrate predators. Oecologia 67: 555-565.

Wiig, O. 1986. Sexual dimorphism in the skull of minks, Mustela vison, badgers, Meles meles, and otters, Lutra lutra. Zoological Journal of the Linnean Society 87: 163-179.

Wiig, O. 1989. Craniometric variation in Norwegian wolverines (Gulo gulo). Zoological Journal of the Linnaean Society 95: 177-204.

Wiig, O. 1992. Carnivore morphometrics: a study of skull variation and its significance. Ph.D. thesis. Zoological Museum, University of Bergen.

Wiig, O, and T. Andersen. 1986. Sexual size dimorphism in the skull of Norwegian lynx. Acta Theriologica 31: 147-155.

Willey, C. H. 1974. Aging black bears from first premolar tooth sections. Journal of Wildlife Management 38: 97-100.

Zaret, T. M. 1980. Predation and freshwater communities. Yale University Press, New Haven.

Received 14 January 2002

Accepted 1 December 2003 